\title{
APLICAÇÃO DO BLUE DYE TEST EM PACIENTES POR FONOAUDIOLOGOS NOS SERVIÇOS BRASILEIROS PÚBLICOS E PRIVADOS.
}

\author{
Karoline Mendonça*, Lucia F. Mourão, Daniella P. Lima.
}

\section{Resumo}

Este projeto teve como objetivo identificar a aplicação do blue dye test na avaliação da deglutição do paciente traqueostomizado por profissionais de fonoaudiologia atuantes nos serviços de saúde do território brasileiro. Os participantes responderem um questionário online sobre o blue dye test, dinamica/ rotina do serviço e caracterização do profissional.

\section{Palavras-chave: Traqueostomia, Broncoaspiração e Blue Dye Test}

\section{Introdução}

A traqueostomia pode altera a deglutição, pois altera o movimento (crânio-caudal) da laringe. A utilização de cânulas com cuff podem gerar certa pressão no esôfago, dificultando a passagem de alimentos.

O blue dye test avalia a deglutição de saliva do paciente traqueostomizado. Este procedimento apresenta uma grande diversidade no método, na faixa etária do paciente e nos seus objetivos. Também apontam variável sensibilidade e especificidade, gerando conflitos em sua interpretação e, consequentemente, no direcionamento da conduta do paciente disfágico.

\section{Resultados e Discussão}

Participaram da pesquisa 145 fonoaudiólogos.

Tabela 1- Relação dos profissionais que podem solicitar outros exames para avaliar o paciente traqueostomizado

\begin{tabular}{l|l|c|c}
\multicolumn{2}{c}{ Variáveis } & N & Porcentagem \\
\cline { 2 - 4 } Solicitação & \begin{tabular}{l}
\multicolumn{1}{|c}{ Videoendoscopia (VED) } \\
exames
\end{tabular} & 73 & 32,90 \\
instrumentais deglutição & Videofluoroscopia/Videod & 56 & 25,20 \\
& eglutograma da & & \\
& deglutição & & 15,30 \\
& Raio X & 34 & 5,40 \\
& Manometria & 12 & 17,60 \\
& Não existe & 39 & 3,60 \\
& Outros & 8 & 100,0
\end{tabular}

A videoendoscopia e a videofluroscopia são medidas mais exatas para detectar broncoaspiração. Possibilitam a liberação das consistências alimentares e manobras facilitadoras, que podem reduzir ou eliminar o risco de penetração ou aspiração. Já o bllue dye test não é um teste fidedigno para aspiração ou penetração de saliva.

Tabela 2. Descrição dos procedimentos de aplicação do blue dye test

\begin{tabular}{l|l|c|cc}
\multicolumn{2}{c}{ Variáveis } & N & Porcentagem \\
\hline \multirow{3}{*}{$\begin{array}{l}\text { Compostos } \\
\text { utilizados }\end{array}$} & Corante alimentício azul & 140 & 92,10 & \\
& Corante alimentício verde & 2 & 1,30 & \\
& Azul de metileno & 10 & 6,60 & 1. \\
& Total de respostas & 152 & 100,00 & \\
\hline \multirow{4}{*}{$\begin{array}{l}\text { Condição do } \\
\text { cuff }\end{array}$} & Totalmente Insuflado & 12 & 7,00 & 2. \\
& Desinsuflado & 107 & 62,60 & \\
& Parcialmente & 18 & 10,50 & \\
& desinsuflado & & & 3. \\
& Todas as opções & 25 & 14,60 & 3. \\
& Outros & 9 & 5,30 & \\
& Total de respostas & 171 & 100,00 &
\end{tabular}

\begin{tabular}{l|c|c} 
Ocluída & 30 & 18,00 \\
Parcialmente ocluída & 9 & 5,40 \\
Sem oclusão & 81 & 48,50 \\
Todas as opções & 37 & 22,20 \\
Outros & 10 & 6,00 \\
Total de respostas & 167 & 100,00 \\
\hline Não específica & 20 & 13,8 \\
2 gotas & 25 & 17,2 \\
3 a 5 gotas & 78 & 53,8 \\
6 a 8 gotas & 8 & 5,5 \\
Outros & 14 & 9,7 \\
Total de respostas & 145 & 100,00
\end{tabular}

Tradicionalmente o protocolo recomenda aplicar 4 gotas de corante alimentício azul na cavidade oral, a cada 4 horas e realiza o monitoramento por 48 horas. Considera que o paciente está broncoaspirando na presença de resíduo azul pela traqueostomia.

O corante azul de metileno pode ocasionar choque anafilático em pacientes renais crônicos. Já o corante alimentício azul seria contra indicado em pacientes com sepse, queimaduras, traumas, choque, intervenções cirúrgicas, insuficiência renal, doença celíaca ou inflamatória intestinal, pois acarreta no aumento da permeabilidade gastrointestinal.

O cuff insuflado afeta os mecanismos de proteção das vias aéreas, alterando o movimento de elevação e anteriorização da laringe, dessensibiliza a laringofaringe, estimula a granulação e acumula secreção.

\section{Conclusões}

Com este estudo foi possível verificar que grande parte da amostra executa o teste conforme a literatura tradicional o descreve e conseguem solicitar exames instrumentais. Para validar o modo de execução do blue dye test mais empregado no território brasileiro, a amostra precisaria ter maior número de participantes.

\section{Agradecimentos}

Agradeço ao SAE/UNICAMP pela colaboração na realização desta pesquisa.

1. Padovani, A.R. et al. Teste do Corante Azul na Avaliação Fonoaudiológica de Indivíduos Traqueostomizados.. $1^{\mathrm{a}}$ ed. São Paulo, Sarvier, 2012. p 240-231.

2. Bingjie, Li et al. Quantitative videofluoroscopic analysis of penetrationaspiration in post-stroke patients. Neurology India, v. 58, n. 1, p. 42, 2010.

3. Barros, A. P. B.; Querija, D. S.; Marinho, M. C. C. R. Caracterização do atendimento fonoaudiológico em pacientes internados. Rev Méd Ana Costa, v. 12, n. 2, p. 34-7, 2007.

4.Maloney, J. P. et al. Food dye use in enteral feedings: a review and a call for a moratorium. Nutrition in Clinical Practice, v. 17, n. 3, p. 169-181, 2002 